\title{
ANALISIS RANTAI PEMASARAN DAN POLA DISTRIBUSI KEPITING BAKAU (Scylla serrata) DI DOBO KABUPATEN KEPULAUAN ARU PROVINSI MALUKU
}

\author{
Billy William $\mathrm{G}^{1}$, Ediyanto ${ }^{2}$ \\ ${ }^{1,2,3)}$ Fakultas Ilmu Kelautan dan Perikanan Universitas Satya Negara Indonesia Jalan \\ Arteri Pondok Indah No:11, Jakarta Selatan 12240 \\ Email:gutandjalabilly@gmail.com
}

\begin{abstract}
Mangroves crab (scyila serrata) is one of fisheries products on habitats coastal waters , particularly in the region mangrove forest ( mangrove ). Crab mangroves as one of the local potential moluccas particularly in the dobo is one of several commodities sales very promising .The crab in marketing mangrove dobo using two the marketing .Marketing efficiency of both the marketing it can look at the marketing of analysis , $\mathrm{B} / \mathrm{C}$ ratio , market share and fisherman's share . On the margin of marketing analysis of both the margin calculation marketing each of the total marketing margins on marketing channel first $\mathrm{Rp}$ 62.100.000 margins and total marketing on marketing channel both Rp 63.300.000, While on a roll call $\mathrm{B} / \mathrm{C}$ ratio of both the marketing the first this marketing of the $\mathrm{Rp} 1,47$ While in marketing outlets both have value of $\mathrm{Rp} 50$.In the calculation on market share of the marketing first show that traders a retailer $(54 \%)$ has an important role in market share of the marketing first, while in marketing outlets second highest market share obtained from traders a retailer of $46 \%$.In the calculation on fisherman's share can be concluded that for both marketing outlets the percentage the results of the received fishermen largest found in marketing outlets second where on this part received by fishers are of the marketing namely agent at $38 \%$.
\end{abstract}

Key words: Crab mangroves, a chain of marketing, the distribution pattern, aru islands

\section{ABSTRAK}

Kepiting bakau (Scylla serrata) merupakan salah satu komoditas perikanan pada habitat perairan pantai, khususnya di daerah hutan bakau (mangrove). Kepiting bakau sebagai salah satu potensi daerah Maluku khususnya di daerah Dobo adalah salah satu dari beberapa komoditas penjualan yang sangat menjanjikan. Sistem pemasaran kepiting bakau di Dobo menggunakan dua saluran pemasaran. Efisiensi pemasaran dari kedua saluran pemasaran ini dapat di lihat dari analisis margin pemasaran, B/C ratio, Market Share dan Fisherman's Share. Pada analisis margin pemasaran dari perhitungan kedua margin pemasaran masingmasing total margin pemasaran pada saluran pemasaran pertama sebesar Rp 62.100.000 dan total margin pemasaran pada saluran pemasaran kedua sebesar Rp 63.300.000 , sedangkan pada hasil perhitungan $\mathrm{B} / \mathrm{C}$ ratio dari kedua saluran pemasaran ini saluran pemasaran pertama memiliki nilai sebesar Rp 1,47 sedangkan pada saluran pemasaran kedua memiliki nilai sebesar Rp 1,35 . Pada hasil perhitungan Market Share pada saluran pemasaran pertama menunjukan bahwa pedagang pengecer (54\%) memegang peranan penting dalam Market Share pada saluran pemasaran pertama, sedangkan pada saluran pemasaran kedua Market Share tertinggi didapatkan dari pedagang pengecer sebesar $46 \%$. Pada hasil perhitungan fisherman's share dapat disimpulkan bahwa untuk kedua saluran pemasaran persentase hasil bagian yang diterima nelayan terbesar terdapat pada saluran pemasaran kedua yang dimana pada hal ini bagian yang diterima oleh nelayan adalah dari lembaga pemasaran yaitu agen sebesar $38 \%$.

Kata kunci: Kepiting Bakau, Rantai Pemasaran, Pola Distribusi, Kepulauan Aru 


\section{PENDAHULUAN}

Kepiting bakau (Scylla serrata) merupakan salah satu komoditas perikanan yang bernilai ekonomis tinggi. Kepiting bakau hidup pada habitat perairan pantai, khususnya di daerah hutan bakau (mangrove). Negara Indonesia adalah salah satu pengekspor kepiting bakau yangcukup besar dibandingkan negara lain (Kanna, 2002). Kepiting bakau adalah salah satu biota laut penghuni tetap kawasan hutan mangrove sehingga dalam menjalani hidupnya sangat bergantung pada kondisi hutan mangrove (Moosa et al, 1985).

Kepiting bakau sebagai salah satu komoditas perikanan yang potensial di daerah Maluku khususnya di kota Dobo. Berdasarkan hasil wawancara yang dilakukan kepada responden dan data yang tersedia di Dinas Kelautan dan Perikanan setempat, permintaan kepiting dari pengusaha restoran seafood di jakarta semakin meningkat dikarenakan daging kepiting tidak saja lezat tetapi juga menyehatkan. Berdasarkan latar belakang tersebut maka penulis akan melakukan penelitian dengan judul "Analisis Pemasaran dan Pola Distribusi Kepiting bakau (Scylla serrata) di Dobo, Kabupaten Kepulauan Aru". Analisis rantai pemasaran dan pola distribusi sangat penting untuk diketahui, karena dengan mengetahui hal tersebut maka dapat disimpulkan seperti apa rantai pemasaran dan pola distribusi yang ada di Dobo. Disamping itu dapat diketahui juga permasalahan-permasalahan apa saja yang akan terjadi dalam suatu usaha dan bagaiamana solusi yang harus di lakukan untuk menyelesaikan permasalahan yang terjadi, selain itu faktor alat transportasi pengiriman dari para pedagang besar ke tempat tujuan pengiriman dan adanya pembatasan dalam kapasitas pengiriman menjadi kendala yang harus ditemui oleh para pelaku usaha perikanan di daerah setempat.

Berdasarkan latar belakang sebagaimana telah dikemukakan, maka dirumuskan pertanyaan dalam penelitian ini, yaitu : Bagaimana sistem pemasaran kepiting bakau (Scylla serrata) yang terjadi di Dobo, Kabupaten Kepulauan Aru? Apakah pemasaran kepiting bakau (Scylla serrata) di Dobo, Kabupaten Kepulauan Aru sudah efisien yang dapat dilihat dari marjin pemasaran, Market's share, rasio keuntungan dan Fisherman' share?

Pada penelitian ini Bagi praktisi, diharapkan dengan penelitian ini maka para pelaku usaha dapat mengetahui gambaran umum sistem pemasaran kepiting bakau dan struktur pasar sehingga nantinya mampu meningkatkan efisiensi pemasaran komoditas kepiting bakau dan mampu meningkatkan kesejahteraan pihak-pihak yang terkait dalam penelian ini dan Bagi instansi, diharapkan penelitian ini dapat berguna bagi Pemerintah Daerah dan Dinas Perikanan setempat dalam menetapkan kebijakan yang berkaitan dengan pemasaran kepiting bakau dari daerah Dobo, Kepulauan Aru. Bagi akademisi, penelitian ini diharapkan dapat menjadi referensi untuk penelitian selanjutnya terutama yang berkaitan dengan rantai pemasaran dan pola distribusi komoditi kepiting bakau.

\section{METODOLOGI}

Penelitian ini dilakukan pada Bulan Oktober 2015 sampai dengan Bulan Desember 2015. Lokasi penelitian dilakukan di Dobo, Kabupaten Kepulauan Aru, Provinsi Maluku. Metode yang digunakan adalah metode deskriptif dapat diartikan sebagai prosedur pemecahan masalah yang diselidiki dengan menggambarkan keadaan subjek atau objek dalam penelitian dapat berupa orang, lembaga, masyarakat dan yang lainnya yang pada saat sekarang berdasarkan fakta-fakta yang tampak atau apa adanya. Data yang dikumpulkan dalam penelitian ini terdiri atas data primer dan sekunder. Data primer dikumpulkan langsung dari lapangan yang terdiri dari data pemasaran hasil tangkapan kepiting bakau (Scylla serrata). Data tersebut diambil menggunakan metode wawancara dan pengamatan langsung di lapangan. Data sekunder yang diambil meliputi data pemasaaran hasil tangkapan kepiting bakau (Scylla serrata) dari tahun 2010 sampai dengan tahun 2014, dari Kantor Dinas Kelautan dan Perikanan Kabupaten Kepulauan Aru. Teknik pengambilan sampel dilakukan 
terhadap nelayan yang mendaratkan hasil tangkapannya di para pedagang besar di daerah Dobo, Kabupaten Kepulauan Aru.

\section{KEADAAN UMUM LOKASI PENELITIAN}

\section{A. Letak dan Keadaan Geografis}

Kepulauan Aru secara administratif terletak di Kelurahan Siwa Lima, Kecamatan Pulau-Pulau Aru, Kota Dobo, Provinsi Maluku. Menurut Astronomi Kepulauan Aru terletak antara $5^{0}-8^{0}$ LS dan $133,5^{0}-136,5^{\circ}$ BT, Luas wilayah Kabupaten Kepulauan Aru \pm $55.270,22 \mathrm{Km}^{2}$ dengan luas daratan $\pm 6.425,77 \mathrm{Km}^{2}$. Secara geografis Kepulauan Aru dibatasi dengan :

$\begin{array}{ll}\text { - Sebelah Selatan } & \text { : Laut Arafura } \\ \text { - Sebelah Utara } & \text { : Bagian Selatan Irian Jaya } \\ \text { - Sebelah Timur } & \text { : Bagian Selatan Irian Jaya } \\ \text { - Sebelah Barat } & \text { : Bagian Timur Pulau Kei Besar dan Laut } \\ & \text { Arafura }\end{array}$

\section{B. Sumber Daya Alam Kabupaten Kepulauan Aru}

Kabupaten Kepulauan Aru memiliki Sumber Daya Alam (SDA) yang sangat kaya dan belum diolah secara maksimal. Kekayaan alam tersebut tersebar merata di seluruh Kepulauan Aru, baik yang ada di daratan maupun lautan. Kabupaten Kepulauan Aru memiliki lahan luas untuk peternakan, perkebunan dan pertanian. Selain itu, Kekayaan Alam berupa Hutan dengan Flora dan Fauna yang sangat kaya dan di lautan Kabupaten Kepulauan Aru dikenal sebagai sumber penghasil komoditi berbagai jenis ikan.

Pemerintah Daerah Kabupaten Kepulauan Aru menyadari bahwa Kekayaan alam yang sangat melimpah akan dapat dimanfaatkan secara optimal jika terdapat kerjasama yang baik antara Pemerintah, sektor swasta dan masyarakat. Hanya dengan kerjasama itu, investasi atau penanaman modal yang masuk ke Kabupaten Kepulauan Aru akan dapat berguna untuk kesejahteraan masyarakat.

\section{Keadaan Hutan Mangrove}

Luas penyebaran hutan mangrove di Maluku adalah 1.322,907 $\mathrm{Km}^{2}$. Sementara luas kawasan hutan mangrove di Kepulauan Aru berdasarkan hasil survei lapangan adalah $833,571 \mathrm{Km}^{2}$ yang terdiri atas vegetasi Rhizophora mucronata, Bruguiera gymnorhiza, Ceriops tagal, Aegiceras comiculatum, Aegiceras floridum, Avicennia alba, Sonneratia alba, Xylocerpus granatum, dan Excoecaria agallocha. Kondisi ekosistem hutan mangrove di kawaan ini sangat mendukung perkembangan dan pertumbuhan biota perairan, sehingga kawasan ini menjadi daerah penangkapan kepiting bagi para nelayan yang berada di sekitar wilayah Kepulauan Aru.

Fauna yang berasosiasi dengan ekosistem hutan mangrove terbagi atas 3 kelompok, yaitu mamalia darat, burung dan biota perairan, selain hasil tangkapan utama yaitu kepiting bakau (Scylla serrata) ada beberapa jenis biota lain yang tertangkap di perairan sekitar hutan mangrove yaitu : ikan kakap, kakap rawa, dan kerapu.

\section{Karakteristik Penduduk Kabupaten Kepulauan Aru}

Kondisi perkembangan penduduk di Kabupaten Kepulauan Aru mengalami pertumbuhan dari Tahun 2009 sampai dengan Tahun 2013. Data jumlah penduduk di Kabupaten Kepulauan Aru disajikan pada Tabel 1 di bawah ini : 
Tabel 1. Data Penduduk Kabupaten Kepulauan Aru

\begin{tabular}{|l|c|c|c|c|c|}
\hline \multirow{2}{*}{ Uraian } & \multicolumn{5}{|c|}{ Tahun } \\
\cline { 2 - 6 } & $\mathbf{2 0 0 9}$ & $\mathbf{2 0 1 0}$ & $\mathbf{2 0 1 1}$ & $\mathbf{2 0 1 2}$ & $\mathbf{2 0 1 3}$ \\
\hline $\begin{array}{l}\text { Jumlah Pria } \\
\text { (jiwa) }\end{array}$ & 42.369 & 43.664 & 44.904 & 46.027 & 46.051 \\
\hline $\begin{array}{l}\text { Jumlah Wanita } \\
\text { (jiwa) }\end{array}$ & 39.337 & 40.474 & 41.564 & 42.665 & 42.688 \\
\hline Total (jiwa) & 81.706 & 84.138 & 86.468 & 88.692 & 88.739 \\
\hline
\end{tabular}

Pada Tahun 2009 total penduduk Kabupaten Kepulauan Aru sebanyak 81.706 jiwa, yang terdiri dari Pria 42.369 jiwa dan Perempuan 39.337 jiwa, pada Tahun 2010 total penduduk Kabupaten Kepulauan Aru sebanyak 84.138 jiwa, yang terdiri dari Pria 43.664 jiwa dan Perempuan 40.474 jiwa, pada Tahun 2011 total penduduk Kabupaten Kepulauan Aru sebanyak 86.468 jiwa, yang terdiri dari Pria 44.904 jiwa dan Perempuan 41.564 jiwa, pada Tahun 2012 total penduduk Kabupaten Kepulauan Aru sebanyak 88.692 jiwa, yang terdiri dari Pria 46.027 jiwa dan Perempuan 42.665 jiwa, dan pada Tahun 2013 total penduduk Kabupaten Kepulauan Aru sebanyak 88.739 jiwa, yang terdiri dari Pria 46.051 jiwa dan Perempuan 42.688 jiwa.

\section{HASIL DAN PEMBAHASAN}

\section{A. Pengoperasian Alat Tangkap}

Alat tangkap bubu lipat yang umum digunakan oleh para nelayan berbentuk kotak dan dengan ukuran yang biasa digunakan oleh nelayan. Jumlah bubu yang dioperasikan sebanyak 24 unit bubu. Bubu lipat yang digunakan mempunyai dimensi P x L x T = 45 x $30 \times 18 \mathrm{~cm}$. Mulut bubu atau funnel berbentuk celah dengan lebar sebesar $1 \mathrm{~cm}$ memanjang secara horizontal dengan panjang $29 \mathrm{~cm}$.

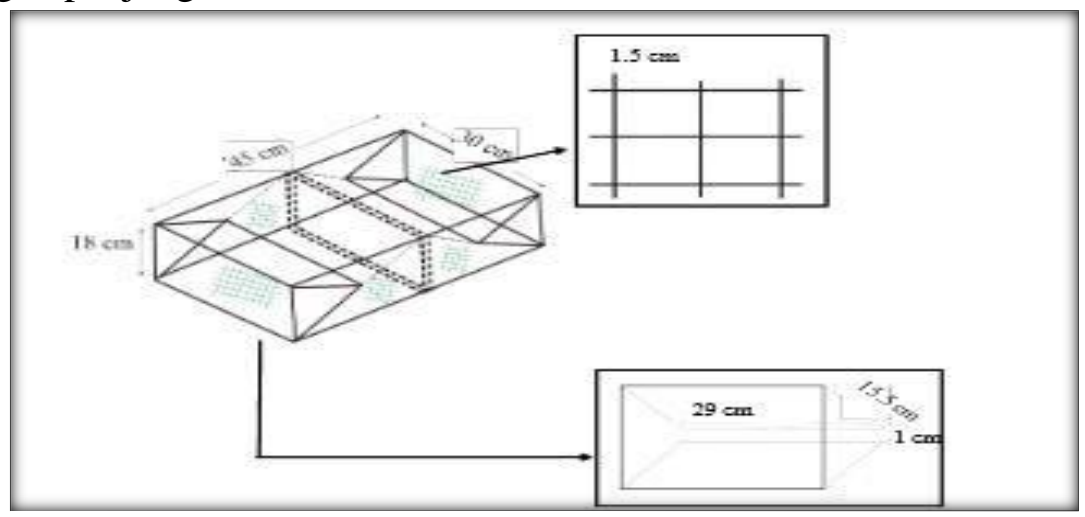

Pengoperasian bubu lipat dilakukan sebanyak 10 trip dengan 2 kali operasi penangkapan per trip, yaitu pada pagi hari dan sore hari. Proses pengoperasian pagi hari dilakukan setting pada pukul 06:00 WIT dan hauling pukul 16:00 WIT serta proses pengoperasian sore hari dilakukan setting pada pukul 17:00 WIT dan hauling pada esok harinya pada pukul 05:00 WIT. Pengoperasian bubu lipat ini dioperasikan dengan sistem tunggal pada kedalaman 1-5 $\mathrm{m}$. Lokasi bubu ditandai dengan adanya pelampung yang terbuat dari busa yang dipasang pada tali pelampung dan diikat pada tiap bubu. Bubu tersebut dipasang pada 6 (enam) stasiun yang terpisah.

\section{B. Penanganan Pasca Penangkapan}

Setelah kepiting tertangkap atau terperangkap pada alat tangkap, kepiting harus ditangani dengan baik dan hati-hati agar tidak melukai dan membuat cacat kepiting, bobot berkurang 
serta tidak melukai nelayan. Kepiting harus dijaga tetap hidup dan tidak stres agar masih bisa dijual atau dikonsumsi. Cara menangani kepiting agar tetap hidup dan tidak stres pada alat tangkap bubu lipat adalah setelah bubu diangkat yang berisi kepiting hidup, bubu disimpan pada tempat yang tidak terpapar matahari secara langsung. Umumnya nelayan kepiting membawa alat penampungan sementara seperti ember. Ember ini disimpan pada tempat yang tidak terkena sinar matahari secara langsung. Penampungan sementara ini adalah penanganan paling awal pasca tangkap untuk menjaga kualitas kepiting agar harganya tetap tinggi.

\section{Pengemasan dan Pengiriman}

Pengemasan dan pengiriman kepiting bakau (Scylla serrata) yang baik akan menjaga mutu dan harga jual kepiting bakau, selain itu dalam pengiriman dan tata cara packing harus mengikuti standar pengiriman (SOP) yang telah ditetapkan pemerintah atau maskapai penerbangan. Pengikatan kepiting bakau melalui nelayan setelah di ikat dan di angkut dengan kapal ke pedagang besar yang ada di Dobo. Pedagang besar akan melakukan sortir, penimbangan dan pengemasan kepiting yang setelah itu akan di distribusikan ke Jakarta menggunakan pesawat terbang. pengemasan menggunakan styrofoam dan di lubangi beberapa titik di setiap sisi styrofoam. Pengiriman kepiting dalam keadaan kering dikarenakan peraturan atau syarat yang sudah ditentukan oleh pihak perusahaan penerbangan.

\section{Sistem Pemasaran}

Sistem pemasaran kepiting bakau di Dobo ini dilakukan dengan sistem satuan rupiah per kilogram $(\mathrm{Rp} / \mathrm{kg})$, maka sistem satuan yang ditetapkan dalam penelitian ini adalah $\mathrm{Rp} / \mathrm{kg}$. Dari responden nelayan dalam penelitian ini ada yang menggunakan jasa pedagang besar untuk mengumpulkan dan menyalurkan hasil produksi kepiting kepada para pedagang pengecer di Jakarta dan ada juga responden nelayan yang menjual hasil tangkapannya kepada para agen terlebih dahulu dan kemudian menjualnya kepada pedagang besar untuk didistribusikan ke Jakarta. Dengan adanya saluran pemasaran ini akan menyebabkan tingkat marjin, biaya pemasaran dan keuntungan yang berbeda, pembagian keuntungan yang adil di antara pelaku dalam pemasaran sangat menentukan untuk menetukan efisiensi pemasaran yang terjadi antara kedua saluran pemasaran yang ada.

\section{E. Saluran Pemasaran}

Saluran pemasaran yang terjadi di Dobo ada dua saluran pemasaran. Saluran pemasaran pertama terdapat nelayan, pedagang besar, pedagang pengecer. Untuk saluran pemasaran kedua terdapat nelayan, agen penunjang, pedagang besar, dan pedagang pengecer.

(1).

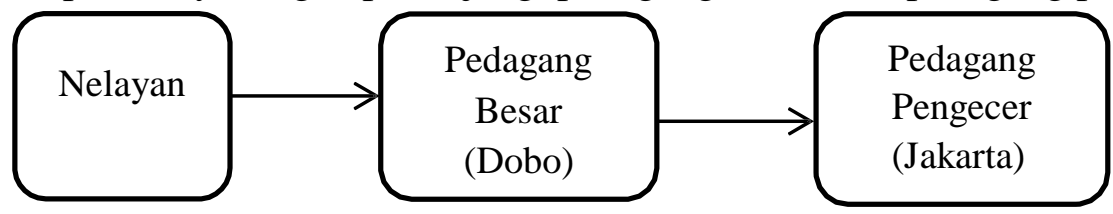

Pada Gambar di atas dapat dilihat pada saluran pemasaran tersebut terjadi rantai pemasaran dimana nelayan sebagai produsen menjual hasil tangkapan yang didapatkan kepada pedagang besar yang ada di Dobo. Setelah melakukan proses transaksi maka pedagang besar melakukan proses penyortiran, penaksiran harga jual dan pengepakan. Proses pengepakan dilakukan dengan prosedur (SOP) yang sudah ada, setelah proses pengepakan selesai maka pedagang besar akan segara melakukan proses pendistribusian ke Jakarta dengan menggunakan transportasi pesawat terbang. 
(2).

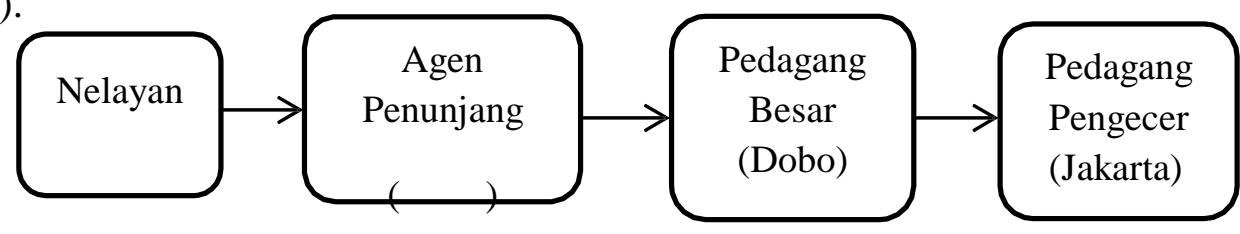

Pada Gambar di atas dapat dijelaskan bahwa saluran pemasaran kepiting bakau yang terdapat di Dobo untuk dikirim ke Jakarta dimana hasil tangkapan nelayan akan di jual kepada agen terlebih dahulu dan selanjutnya agen penunjang akan menyalurkan hasil tangkapan kepiting ini kepada pedagang besar di Dobo, untuk proses dari pedagang besar kepada pedagang pengecer yang terdapat di Jakarta proses yang digunakan sama seperti yang sudah dibahas pada saluran pemasaran yang pertama dimana setelah melakukan transaksi pembelian maka pedagang besar akan melakukan proses pengepakan untuk dikirim ke Jakarta.

Pedagang pengecer kemudian akan melakukan proses penjualan dimana kepiting akan di jual kepada lembaga usaha yang ada di wilayah Jakarta. Dalam hal ini adalah mereka yang menjual hasil tangkapan kepiting bakau dalam bentuk siap saji kepada para konsumen, lembaga usaha tersebut adalah pihak hotel dan restoran, dimana dalam hal ini hotel dan restoran Seafood yang nantinya akan menjual kepiting bakau kepada konsumen dalam bentuk siap saji. Untuk hasil tangkapan yang kurang memenuhi standar atau tidak layak untuk di distribusikan ke Jakarta para pedagang besar di Dobo menjual kepiting yang mereka kumpulkan untuk dijual ke pasar-pasar lokal yang ada di Dobo.

\section{F. Analisis Marjin Pemasaran}

Marjin pemaran sering digunakan sebagai indikator efisiensi pemasaran. Besarnya marjin pemasaran pada berbagai saluran pemasaran dapat berbeda, karena tergantung pada panjang pendeknya saluran pemasaran dan aktivitas-aktivitas yang telah dilaksanakan serta keuntungan yang didapatkan.

Pada Tabel 2 dan 3 berikut ini dapat dilihat hasil analisis marjin, distribusi marjin, share harga yang diterima nelayan serta ratio keuntungan dan biaya dalam pemasaran kepiting bakau.

Tabel 1. Analisis Margin Saluran Pemasaran Pertama

\begin{tabular}{|l|c|c|c|c|}
\hline \multicolumn{1}{|c|}{ Uraian } & $\begin{array}{c}\text { Total } \\
\text { Pendapatan }\end{array}$ & $\begin{array}{c}\text { Total Biaya } \\
\text { Pemasaran }\end{array}$ & Keuntungan & $\begin{array}{c}\text { Margin } \\
\text { Pemasaran }\end{array}$ \\
\hline Nelayan & Rp 19.200.000 & Rp 6.755.000 & Rp 12.445.000 & \\
\hline $\begin{array}{l}\text { Pedagang } \\
\text { Besar }\end{array}$ & Rp 60.000 .000 & $R p ~ 31.325 .000$ & Rp 28.675.000 & Rp 40.800.000 \\
\hline $\begin{array}{l}\text { Pedagang } \\
\text { Pengecer }\end{array}$ & Rp 81.300.000 & Rp 71.140.000 & Rp 10.160.000 & Rp 21.300.000 \\
\hline
\end{tabular}

Berdasarkan Tabel 12 di atas untuk nelayan saluran pemasaran pertama dengan total pendapatan sebesar Rp 19.200.000 dikurangi total biaya pemasaran sebesar Rp 6.755.000 maka nelayan mendapat keuntungan sebesar $\mathrm{Rp} 12.445 .000$, sedangkan untuk pedagang besar dengan pendapatan sebesar Rp 60.000.000 dikurangi dengan total biaya pemasaran sebesar Rp 31.325.000 maka mendapatkan keuntungan sebesar Rp 28.675.000 dan margin pemasaran yang didapatkan oleh pedagang besar sebesar $\mathrm{Rp} 40.800 .000$ dimana hasil tersebut didapat dari pendapatan di tingkat pedagang besar sebesar Rp 60.000.000 dikurangi dengan pendapatan di tingkat nelayan sebesar Rp 19.200.000 dan untuk pedagang pengecer di Jakarta dengan total pendapatan sebesar Rp 81.300.000 dikurangi dengan total biaya 
pemasaran sebesar Rp 71.140.000 maka mendapatkan keuntungan sebesar Rp 10.160.000 dan margin yang didapatkan sebesar Rp 21.300.000, dimana hasil tersebut didapat dari pendapatan di tingkat pedagang pengecer sebesar Rp 81.300.000 dikurangi dengan pendapatan di tingkat pedagang besar yang ada di Dobo sebesar Rp 60.000.000.

Tabel 3. Analisis Margin Saluran Pemasaran Kedua

\begin{tabular}{|c|c|c|c|c|}
\hline Uraian & $\begin{array}{c}\text { Total } \\
\text { Pendapatan }\end{array}$ & $\begin{array}{l}\text { Total Biaya } \\
\text { Pemasaran }\end{array}$ & Keuntungan & $\begin{array}{c}\text { Margin } \\
\text { Pemasaran }\end{array}$ \\
\hline Nelayan & Rp 18.000.000 & Rp 6.155 .000 & Rp 11.845.000 & \\
\hline Agen Penunjang & Rp 23.400.000 & $\operatorname{Rp} 21.150 .000$ & $\begin{array}{ll}\mathrm{Rp} & 2.250 .000\end{array}$ & Rp 5.400 .000 \\
\hline Pedagang Besar & Rp 64.800.000 & $\operatorname{Rp} 35.525 .000$ & Rp 29.275.000 & Rp 41.400.000 \\
\hline $\begin{array}{l}\text { Pedagang } \\
\text { Pengecer }\end{array}$ & $\operatorname{Rp} 81.300 .000$ & Rp 75.940.000 & Rp 5.360 .000 & Rp 16.500.000 \\
\hline
\end{tabular}

Dari Tabel 3 di atas dapat diketahui bahwa pada saluran pemasaran kedua dengan pendapatan di tingkat nelayan sebesar Rp 18.000.000 dan biaya pemasaran sebesar Rp 6.155.000 maka keuntungan yang didapatkan sebesar Rp 11.845.000, sedangkan untuk agen penunjang dengan pendapatan sebesar Rp 23.400.000 dan biaya pemasaran sebesar Rp 21.150.000 maka keuntungan yang diperoleh sebesar Rp 2.250.000 dan margin pemasaran yang didapatkan dari agen penunjang sebesar Rp 5.400.000 , untuk pedagang besar dengan pendapatan sebesar Rp 64.800.000 dikurangi dengan biaya pemasaran sebesar Rp 35.525.000 maka keuntungan yang didapatkan sebesar Rp 29.275.000 dan untuk margin pemasaran yang diperoleh dari agen penunjang sebesar Rp 41.400.000 dimana hasil tersebut diperoleh dari pendapatan di tingkat pedagang besar Rp 64.800.000 dikurangi dengan pendapatan di tingkat agen sebesar Rp 23.400.000. Sementara untuk pedagang pengecer dengan pendapatan sebesar Rp 81.300.000 dan biaya pemasaran sebesar Rp 75.940.000 maka keuntungan yang diperoleh sebesar Rp 5.360.000 dan untuk margin pemasaran yang diperoleh dari pedagang pengecer didapatkan dari hasil pengurangan antara pendapatan dari pedagang besar sebesar $\mathrm{Rp}$ 64.800.000 dan pendapatan dari pedagang pengecer sebesar Rp 81.300.000 maka diperoleh hasil sebesar Rp 16.500.000

Dari perhitungan kedua margin pemasaran diatas masing-masing total margin pemasaran pada saluran pemasaran pertama sebesar $\mathrm{Rp} 62.100 .00$ dan total margin pemasaran pada saluran pemasaran kedua sebesar Rp 63.300.000 , jadi bisa disimpulkan bahwa total margin pemasaran pada saluran pemasaran kedua lebih besar dibandingkan dengan total margin pemasaran pada saluran pemasaran pertama. Hal ini dikarenakan pada saluran pemasaran kedua terdapat agen penunjang yang dimana agen disini adalah faktor pembeda kenapa total margin pemasaran pada masing-masing saluran pemasaran ini berbeda.

\section{G. Analisis Benefit Cost Ratio (B/C Ratio)}

Rasio keuntungan dan biaya merupakan salah satu alat analisis yang digunakan oleh peneliti untuk mengukur efisiensi pemasaran. Rasio ini membandingkan antara keuntungan yang diambil oleh lembaga pemasaran dengan besarnya biaya yang dikeluarkan oleh masingmasing lembaga pemasaran. Saluran pemasaran dikatakan efisien apabila jika perbandingan antara keuntungan dengan biaya yang dikeluarkan oleh lembaga pemasaran dalam satu saluran pemasaran menunjukkan angka yang relatif sama (pembagian keuntungan adil). Berikut ini dapat dilihat rasio keuntungan untuk kedua saluran pemasaran yang tersaji pada Tabel 4. 
Tabel 4. Benefit Cost Ratio (B/C Ratio)

\begin{tabular}{|l|c|}
\hline \multicolumn{1}{|c|}{ Uraian } & B/C \\
\hline Saluran Pemasaran Pertama & 1,47 \\
\hline Saluran Pemasaran Kedua & 1,35 \\
\hline
\end{tabular}

Berdasarkan dari Tabel 14 diatas saluran pemasaran pertama perhitungan $\mathrm{B} / \mathrm{C}$ yang didapat adalah dari total pendapatan $\mathrm{Rp} 160.500 .000$ dibagi dengan total biaya produksi sebesar Rp 109.220.000 maka didapatkan sebesar 1,47, dimana hasil tersebut menunjukkan bahwa dari Rp 1 yang dikeluarkan maka akan mendapatkan Rp 1,47, sedangkan hasil perhitungan $\mathrm{B} / \mathrm{C}$ yang didapatkan oleh saluran pemasaran kedua dari total pendapatan sebesar Rp 187.500.000 dibagi dengan total biaya produksi sebesar Rp 138.770 .000 adalah 1,35 , dimana hasil tersebut menunjukkan bahwa dari $\mathrm{Rp} 1$ yang dikeluarkan maka akan mendapatkan $\mathrm{Rp}$ 1,35 . Menurut hasil perhitungan diatas maka hasil B/C yang diperoleh dari kedua saluran pemasaran tersebut dikatakan layak/menguntungkan karena hasil dari masingmasing saluran pemasaran lebih besar dari 1, dimana dalam kriteria B/C, bila B/C lebih besar dari 1 maka usaha itu dikatakan layak/menguntungkan. Dari kedua saluran pemasaran ini saluran pemasaran pertama memiliki nilai lebih besar dibandingkan dengan saluran pemasaran kedua yang berarti saluran pemasaran pertama memiliki keuntungan lebih besar dibandingkan dengan saluran pemasaran kedua. Perbedaan persentase B/C pada masingmasing saluran pemasaran ini dikarenakan total biaya yang dikeluarkan oleh masing-masing lembaga pemasaran berbeda-beda satu sama lainnya, selain itu faktor harga yang ditawarkan masing-masing saluran pemasaran ini juga sangat berbeda, maka oleh sebab itu faktor tersebut menjadi penentu kenapa $\mathrm{B} / \mathrm{C}$ di masing-masing saluran pemasaran ini sangat berbeda.

\section{H. Market's Share}

Market's Share merupakan proporsi kemampuan lembaga pemasaran terhadap keseluruhan penjualan seluruh pesaing, atas dasar angka tersebut dapat diketahui kedudukan lembaga pemasaran dan kedudukan pesaing-pesaingnya di pasar. Sehingga seringkali tingkat Market Share dapat digunakan sebagai pedoman atau standar keberhasilan suatu pemasaran lembaga pemasaran. Berikut ini disajikan Tabel Market Share pada Tabel 5 dan 6 dibawah ini :

Tabel 5. Market Share Pada Saluran Pemasaran Pertama

\begin{tabular}{|l|c|}
\hline \multicolumn{1}{|c|}{ Saluran Pemasaran } & Market Share \\
\hline Nelayan & $\mathbf{6 \%}$ \\
\hline Pedagang Besar & $\mathbf{4 0 \%}$ \\
\hline Pedagang Pengecer & $\mathbf{5 4 \%}$ \\
\hline
\end{tabular}

Berdasarkan pada Tabel 5 di atas Market Share pada saluran pertama dari persentase penjualan sebesar 100\% Market Share nelayan sebesar 6\%, pedagang besar sebesar $40 \%$ dan pedagang pengecer sebesar 54\%. Hasil perhitungan Market Share didapatkan dari total hasil penjualan atas harga jual di setiap lembaga pemasaran, dalam Market Share pada saluran pemasaran pertama menunjukan bahwa pedagang pengecer memegang peranan penting dalam Market Share pada saluran pemasaran pertama. 
Tabel 6. Market Share Pada saluran Pemasaran Kedua

\begin{tabular}{|l|c|}
\hline \multicolumn{1}{|c|}{ Saluran Pemasaran } & Market Share \\
\hline Nelayan & $\mathbf{5 \%}$ \\
\hline Agen Penunjang & $\mathbf{1 3 \%}$ \\
\hline Pedagang Besar & $\mathbf{3 6 \%}$ \\
\hline Pedagang Pengecer & $\mathbf{4 6 \%}$ \\
\hline
\end{tabular}

Berdasarkan pada Tabel 6 di atas Market Share pada saluran kedua dari persentase penjualan sebesar 100\% Market Share nelayan sebesar 5\%, agen penunjang sebesar 13\%, pedagang besar sebesar $36 \%$ dan pedagang pengecer sebesar $46 \%$. Hasil perhitungan Market Share didapatkan dari total hasil penjualan atas harga jual di setiap lembaga pemasaran, dalam Market Share pada saluran pemasaran kedua menunjukan bahwa pedagang pengecer memegang peranan penting dalam Market Share pada saluran pemasaran kedua. Jadi dapat disimpulkan bahwa Market Share pada dua saluran pemasaran ini pedagang pengecer memegang peranan penting dalam Market Share.

\section{Fisherman's Share}

Fisherman's Share berfungsi untuk melihat seberapa besar persentase bagian yang diterima nelayan. Nilai Fisherman's Share diperoleh dengan membandingkan antara harga di tingkat nelayan dengan harga di tingkat konsumen akhir. Semakin besar nilai Fisherman' Share, maka kinerja pasar semakin baik atau efisien dari sisi nelayan. Berikut ini disajikan dalam Tabel 7 nilai Fisherman's Share:

Tabel 7. Fisherman's Share Pada Saluran Pemasaran Pertama

\begin{tabular}{|l|c|cc|c|}
\hline \multicolumn{1}{|c|}{ Saluran Pemasaran } & $\begin{array}{c}\text { Harga di Tingkat } \\
\text { Nelayan }(\mathrm{Rp} / \mathrm{Kg})\end{array}$ & $\begin{array}{c}\text { Harga di Tingkat } \\
\text { Lembaga Pemasaran } \\
(\mathrm{Rp} / \mathrm{Kg})\end{array}$ & Fisherman's Share(\%) \\
\hline Nelayan & $\mathrm{Rp} \quad 160.000$ & \multicolumn{2}{|c|}{} & \\
\hline Pedagang Besar & & $\mathrm{Rp}$ & 1.010 .000 & $\mathbf{1 6 \%}$ \\
\hline Pedagang Pengecer & & $\mathrm{Rp}$ & 1.355 .000 & $\mathbf{1 2 \%}$ \\
\hline
\end{tabular}

Berdasarkan Tabel 7 di atas dengan harga yang diterima nelayan sebesar Rp 160.000 dan harga yang ditentukan oleh pedagang besar sebesar $\mathrm{Rp} 1.010 .000$ maka fisherman's share yang diperoleh nelayan sebesar $16 \%$, sedangkan untuk fisherman's share yang diperoleh dari nelayan atas harga yang ditentukan oleh pedagang pengecer sebesar Rp 1.355.000 adalah sebesar 12\%. Dari hasil perhitungan fisherman's share diatas dapat disimpulkan bahwa fisherman's share yang diterima nelayan lebih besar didapatkan dari pedagang besar.

Tabel 8. Fisherman's Share Pada Saluran Pemasaran Kedua

\begin{tabular}{|l|c|lc|c|}
\hline \multicolumn{1}{|c|}{ Saluran Pemasaran } & $\begin{array}{c}\text { Harga di Tingkat } \\
\text { Nelayan }(\mathrm{Rp} / \mathrm{Kg})\end{array}$ & $\begin{array}{c}\text { Harga di Tingkat Lembaga } \\
\text { Pemasaran }(\mathrm{Rp} / \mathrm{Kg})\end{array}$ & Fisherman's Share $(\%)$ \\
\hline Nelayan & $\mathrm{Rp} 150.000$ & & & \\
\hline Agen Penunjang & & $\mathrm{Rp}$ & 390.000 & $\mathbf{3 8 \%}$ \\
\hline Pedagang Besar & & $\mathrm{Rp}$ & 1.080 .000 & $\mathbf{1 4 \%}$ \\
\hline Pedagang Pengecer & & $\mathrm{Rp}$ & 1.355 .000 & $\mathbf{1 1 \%}$ \\
\hline
\end{tabular}

Berdasarkan Tabel 8 di atas dengan harga yang diterima nelayan sebesar Rp 150.000 dan harga jual yang ditentukan agen penunjang sebesar Rp 390.000 maka fisherman's share yang diperoleh sebesar 38\%, sedangkan dengan harga jual yang ditentukan oleh pedagang besar sebesar Rp 1.080.000 maka fisherman's share yang diperoleh nelayan sebesar $14 \%$ dan 
fisherman's share sebesar $11 \%$ yang didapatkan nelayan diperoleh dari harga jual yang ditentukan oleh pedagang pengecer. Dari hasil perhitungan fisherman's share diatas dapat kita simpulkan bahwa untuk saluran pemasaran kedua persentase bagian yang diterima oleh nelayan dari agen penunjang sebesar $38 \%$ adalah persentase terbesar dari persenatse fisherman's share lembaga pemasaran lain. Jadi dapat disimpulkan dari perhitungan fisherman's share kedua saluran pemasaran diatas persentase bagian yang diterima nelayan terbesar diperoleh agen penunjang pada saluran pemasaran kedua, hal ini disebabkan karena dengan harga beli yang murah dari nelayan dan harga jual yang ditentukan agen penunjang tinggi maka persentase bagian yang diterima nelayan akan besar.

\section{A. Kesimpulan}

\section{KESIMPULAN DAN SARAN}

Sistem pemasaran kepiting bakau (Scylla serrata) di Dobo menggunakan dua saluran pemasaran, yaitu saluran pemasaran pertama dimana dari nelayan lalu akan dijual kepada para pedagang besar, setelah melakukan penyortiran dan pengepakan pedagang besar langsung mendistribusikan kepada para pedagang pengecer yang ada di Jakarta, sedangkan untuk saluran pemasaran kedua hasil penangkapan kepiting bakau dari nelayan dijual kepada para agen penunjang yang dimana nantinya akan dijual kepada para pedagang besar yang berada di Dobo, kemudian dari para pedagang besar mendistribusikan kepiting bakau ini kepada para pedagang pengecer yang ada di Jakarta. Pada proses pendistribusian ke Jakarta pedagang besar menggunakan alat transportasi udara yaitu pesawat terbang.

Efisiensi pemasaran dari kedua saluran pemasaran ini dapat di lihat dari analisis margin pemasaran, B/C ratio, Market Share dan Fisherman's Share. Pada analisis margin pemasaran dari perhitungan kedua margin pemasaran pada saluran pemasaran pertama sebesar Rp 62.100.000 dan total margin pemasaran pada saluran pemasaran kedua sebesar $\mathrm{Rp}$ 63.300.000, sedangkan pada hasil perhitungan $\mathrm{B} / \mathrm{C}$ ratio dari kedua saluran pemasaran ini saluran pemasaran pertama memiliki nilai sebesar Rp 1,47 sedangkan pada saluran pemasaran kedua memiliki nilai sebesar Rp 1,35 . Pada hasil perhitungan Market Share pada saluran pemasaran pertama menunjukan bahwa pedagang pengecer (54\%) memegang peranan penting dalam Market Share pada saluran pemasaran pertama, sedangkan pada saluran pemasaran kedua Market Share tertinggi didapatkan dari pedagang pengecer sebesar 46\%. Perhitungan fisherman's share hasil bagian yang diterima nelayan terbesar terdapat pada saluran pemasaran kedua yang dimana pada hal ini bagian yang diterima oleh nelayan adalah dari lembaga pemasaran yaitu agen sebesar 38\%. Persentase fisherman's share tersebut adalah persentase terbesar dari lembaga-lembaga pemasaran lain. Jadi semua dapat disimpulkan bahwa kedua saluran pemasaran yang ada di Dobo termasuk dalam kategori efisien dalam pemasarannya.

\section{B. Saran}

Adanya bantuan modal dari pemerintah daerah atau lembaga keuangan kepada nelayan, karena dengan begitu tidak ada lagi nelayan yang meminjam modal untuk melakukan usaha penangkapan dan untuk kehidupan sehari-hari. Pemberian fasilitas dari pemerintah daerah setempat berupa Keramba Jaring Apung (KJA) kepada nelayan yang nantinya dapat digunakan untuk mengumpulkan hasil tangkapannya, disamping itu dengan adanya KJA maka nelayan mampu menjaga kualitas dan memberikan nilai jual yang lebih tinggi kepada pedagang besar. Diperlukan penelitian lanjutan mengenai Analisis Rantai Pemasaran dan Pola Distribusi Kepiting Bakau (Scylla serrata) khususnya di daerah Dobo, Kabupaten Kepulauan Aru. 


\section{DAFTAR PUSTAKA}

Kanna, I., 2002, Budidaya Kepiting Bakau, Penerbit Kanisius, Yogyakarta

Moosa, M.K., Aswandy, I., dan Kasry, A., 1985. Kepiting Bakau, Scylla serrata Forsskal dari Perairan Indonesia. LON-LIPI, Jakarta 18p. 